\title{
LESSON 26
}

For the attention of

PAPER: A5 $(210 \times 148 \mathrm{~mm})$.

MARGINS: Pica, 10; Elite, 15

Turn up 7 single lines before starting.

Write or type in the instructions and keep the sheet for reference.

'For the attention of' may or may not be underscored.

Letter 7

PAPER: A4.

MARGINS: Suitable.

TODAY'S DATE

TARGET TIME: 15 minutes.

Turn up 13 single-line spaces to allow for the printed heading.
Some companies have a rule that all correspondence must be addressed to the company and not to a particular person. Someone who wishes to reach a particular person or department in the company must type the words 'For the attention of' on the letter. This is typed on a separate line 2 spaces below the last line of the inside address. Turn up 2 single-line spaces after 'For the attention of' before you type the salutation.

M. Jukes \& Co. Ltd. ,

23 Wolverhampton Road,

Birmingham. BL4 9WR

(Turn up 2 single lines)

For the attention of Miss B. Bond

(Turn up 2 single lines)

Dear Sirs,

(Turn up 2 single lines)

With reference to the recent visit

Ref. RJ/MP

(Turn up 3 single lines)

To-day's date

(Turn up 3 single lines)

Messrs. James \& Caddick,

Forge Works,

Green Lane,

Barking. BA9 5GL

(Turn up 2 single lines)

For the attention of Mrs. M. Price

(Turn up 2 single lines)

Dear Sirs,

We would like to call your attention to our new range of Office Furniture, details of which are fully illustrated in the enclosed catalogue.

You will observe that every need is carefully catered for and that the emphasis is on good taste and practicality. All the furniture is made as a result of scientific tests on the correct heights of chairs and all working surfaces. Every effort has been made to produce furniture which will remove the fatigue element, as far as possible, from routine office tasks. All desks and seats are adjustable to meet the requirements of individuals and the measurements have been carefully worked out. You will see that all our furniture is available in both wood and metal.

We are prepared to offer generous discount both on bulk purchases and on your existing furniture. If you have any queries, please do not hesitate to contact us. Yours faithfully, OFFICE FURNITURE LTD. Ray James Manager Enc. 